\title{
Comunicação entre a equipe de enfermagem e fami- liares de pacientes em unidade de terapia intensiva
}

\section{Comunicación entre el personal y familiares de pacientes de enfermería en la unidad de cuidados intensivos}

\section{Communication between the nursing staff and relatives of patients in the intensive care unit}

\author{
Laura Cristhiane Mendonça Rezende ${ }^{1}$, Kátia Neyla de Freitas Macedo Costa ${ }^{2}$, \\ Kaisy Pereira Martins ${ }^{3}$, Tatiana Ferreira da Costa ${ }^{3}$
}

\begin{abstract}
${ }^{1}$ Enfermeira. Mestranda do Programa de Pós-graduação em Enfermagem da Universidade Federal da Paraíba. ${ }^{2}$ Doutora em Enfermagem. Professora Efetiva do Departamento de Enfermagem Clínica e do Programa de Pós-Graduação em Enfermagem da UFPB.
\end{abstract}

${ }^{3}$ Enfermeira. Mestranda do Programa de Pós-Graduação em Enfermagem da UFPB.

Cómo citar este artículo en edición digital: Mendonça Rezende, L.C; De Freitas Macedo Costa, K.N; Pereira Martins, K; Ferreira da Costa, T. (2014) Comunicação entre a equipe de enfermagem e familiares de pacientes em unidade de terapia intensiva. Cultura de los Cuidados (Edición digital) 18, 39. Disponible en: http://dx.doi.org/10.7184/cuid.2014.39.10>

Correspondencia: Universidade Federal da Paraíba. UFPB. João Pessoa, Brazil. Telefone: 8854-7002. Correo electrónico: lauracristhiane@hotmail.com

Recibido: 12/01/2014; Aceptado: 16/03/2014

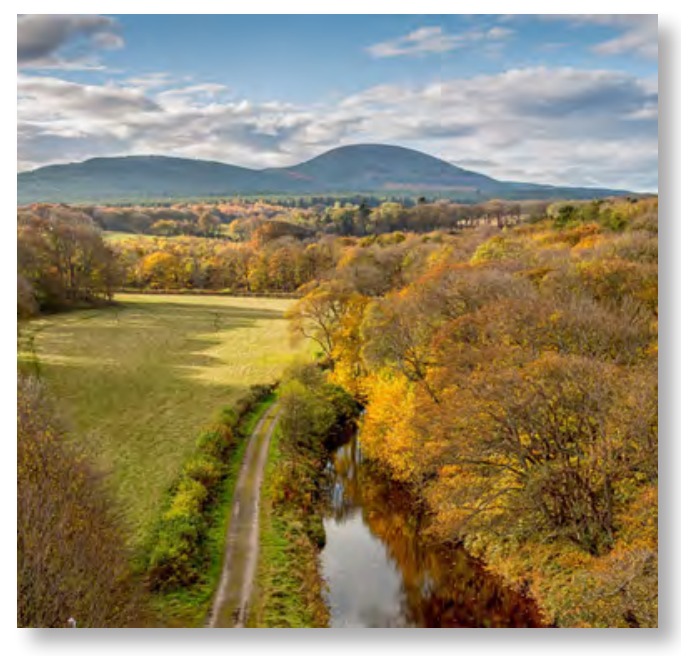

\section{ABSTRACT}

The intensive care unit (ICU) is an environment in which the technique is more aspects of care. In this perspective, it is important to use communication in nursing, awakening a bond of trust between family and professional. Given this reality aimed to analyze the communication between the nursing staff and the relatives of ICU patients. The descriptive is qualitative approach in the ICU of a teaching hospital. Participants were thirty families of ICU patients. Data were collected through semi-structured interviews in September 2011 and analyzed using content analysis. It was found that family members do not receive nursing guidelines on the environment and health of the patient, and also does not provide time to interact during visits. Thereby the emerging need to encourage the training of these professionals to the conscious use of communication.

Keywords: Health communication; Nursing care; Intensive care unit; Family relationships.

\section{RESUMEN}

La unidad de cuidados intensivos (UCI) es un entorno en el que la técnica ocupa más aspectos de la atención enfermera. En este contexto, es importante la utilización de la comunicación en enfermería, despertando un 
vínculo de confianza entre la familia y el profesional. Ante esta realidad se plantea el objetivo de analizar la comunicación entre el personal de enfermería y familiares de los pacientes ingresados en la UCI. La investigación es de tipo cualitativa descriptiva en la UCI de un hospital de enseñanza clínica. Los participantes fueron treinta familias de los pacientes de la UCI. Los datos fueron recolectados a través de entrevistas semi-estructuradas en septiembre de 2011 y se analizaron mediante análisis de contenido. Se encontró que los miembros de la familia no reciben directrices de enfermería sobre el medio ambiente y la salud del paciente, y no proporciona tiempo para interactuar durante las visitas. De forma que existe la necesidad emergente de fomentar la formación de estos profesionales para el uso consciente de la comunicación.

Palabras clave: Comunicación de la Salud; Cuidados de enfermería; Unidad de Cuidados Intensivos; Las relaciones familiares.

\section{RESUMO}

A unidade de terapia intensiva (UTI) é um ambiente em que a técnica se sobrepõe aos aspectos do cuidado. Nessa perspectiva, é fundamental o uso da comunicação pela enfermagem, despertando um elo de confiança entre os familiares e o profissional. Diante dessa realidade objetivou-se analisar a comunicação entre a equipe de enfermagem e os familiares de pacientes em UTI. A pesquisa é descritiva com abordagem qualitativa realizada na UTI de um Hospital Escola. Participaram do estudo trinta familiares de pacientes em UTI. Os dados foram coletados por meio de entrevista semiestruturada em setembro de 2011 e analisados pela técnica de análise de conteúdo. Verificou-se que os familiares não recebem orientações da enfermagem sobre o ambiente e estado de saúde do paciente, e também não disponibiliza tempo para interagir durante as visitas. Desse modo, emerge a necessidade de incentivar a capacitação desses profissionais para o uso consciente da comunicação.

Palavras chave: Comunicação em saúde; Cuidados de enfermagem; Unidade de terapia intensiva; Relações familiares.

\section{INTRODUÇÃO}

A Unidade de Terapia Intensiva (UTI) é considerada uma das unidades de internação mais complexa e mecanizada da estrutura hospitalar, o que pode ser explicado, principalmente, pela gravidade dos pacientes que nela estão internados e pela quantidade de equipamentos utilizados em benefício dos mesmos, para que assim possa aumentar as chances de recompor a estabilidade do paciente crítico e de propiciar sua recuperação e sobrevivência (Martins; Nascimento, 2005; Costa; Figueiredo; Schaurich, 2009).

Com o avanço da tecnologia, a UTI tornou-se um ambiente em que a técnica se sobrepõe aos aspectos interacionais do cuidado, uma vez que os profissionais que ali desenvolvem suas ações estão constantemente lidando com máquinas e procedimentos de alta complexidade e tendem a não ter como foco o binômio paciente e família. No entanto, a internação neste ambiente, parece ser um acontecimento difícil e significativo na dinâmica familiar, já que a família, extensão do paciente, núcleo de interação do mesmo, é afastada do seu convívio por imposição das rigorosas rotinas do serviço (Costa; Figueiredo; Schaurich, 2009; Nascimento; Trentini, 2004).

Desse modo, os sentimentos de preocupação e aflição dos familiares, muitas vezes são maiores que os do próprio paciente. Constata- 
-se que vários aspectos são responsáveis por causar estes desequilíbrios aos parentes, como por exemplo, desconhecer o real estado do paciente; as experiências anteriores de hospitalização de um familiar ou pessoa próxima; a gravidade da condição do paciente; e o contato reduzido com o parente e a equipe da unidade (Oliveira et al., 2005).

Nessa perspectiva, a comunicação é um aspecto fundamental do cuidado de enfermagem que traz ao paciente e seus parentes, que estão vivenciando a hospitalização, a possibilidade de interagir com os profissionais que cuidam do indivíduo, visando ter consciência da situação do mesmo e evitando ampliar sentimentos negativos por parte da família. A comunicação objetiva reconhecer as necessidades do familiar, além de despertar um elo de confiança entre os sujeitos (Oriá; Moraes; Victor, 2004).

Diante desse contexto, este estudo teve como questão norteadora: de que maneira está sendo realizada a comunicação entre profissionais de enfermagem e familiares de pacientes em UTI?

Partindo desse questionamento, destaca-se a relevância da interação e comunicação entre a equipe de enfermagem e os familiares de pacientes internados em UTI, uma vez que estes aspectos poderão minimizar os medos, angústias e expectativas da família diante do estresse e sofrimento causado pela separação e falta de informações sobre o ente querido. Portanto, o presente estudo teve como objetivo analisar a comunicação entre a equipe de enfermagem e os familiares de pacientes em UTI.

\section{METODOLOGIA}

Trata-se de um estudo de natureza descritiva com abordagem qualitativa. A pesquisa foi realizada em um hospital escola, localizado no município de João Pessoa-PB, na Unidade de Terapia Intensiva da instituição. A escolha dessa unidade é justificada pelas condições críticas de saúde dos pacientes, e consequentemente fragilidade emocional de seus familiares. Fizeram parte do estudo trinta familiares, selecionados a partir dos seguintes critérios: já tivesse realizado pelo menos uma visita ao paciente na UTI, maiores de 18 anos e aceitaram participar da pesquisa assinando o Termo de Consentimento Livre e Esclarecido.

O pesquisador permanecia durante o horário da visita, na sala de espera para identificar quem eram os familiares que fizeram as visitas. Em seguida, o familiar era convidado para participar de uma entrevista individual. Os dados foram coletados em setembro de 2011. Utilizou-se um roteiro de entrevista semiestruturado, com o auxilio de um dispositivo eletrônico para a gravação das falas dos entrevistados, contendo questões relacionadas à comunicação realizada entre a equipe de enfermagem e os familiares de pacientes em UTI.

A análise dos dados foi realizada por meio da análise de conteúdo, buscando alcançar a interpretação mais profunda do fenômeno, para isso procurou-se descobrir a relação existente entre o exterior e o próprio discurso, envolvendo também operações de desmembramento e de classificação de suas unidades de registro. Desta forma, desenvolveu as seguintes etapas: primeiramente, foram realizadas leituras para a organização do material a ser analisado, retomando os objetivos iniciais da pesquisa frente ao material coletado, em seguida foi realizada uma releitura ininterrupta dos dados coletados procurando identificar as categorias, as quais foram construídas e rotuladas, a partir das falas dos familiares (Bardin, 2009).

Os participantes foram codificados com letras do alfabeto e números arábicos, de forma a 
garantir seu anonimato e atender às exigências da Resolução no 196/96 do Conselho Nacional de Saúde, que dispõe sobre as normas e diretrizes regulamentadoras de pesquisas envolvendo os seres humanos (Brasil, 1996). O projeto do qual deriva este estudo obteve aprovação do Comitê de Ética em Pesquisa do Hospital Escola no qual o estudo foi desenvolvido e está registrado sob o protocolo $\mathrm{n}^{\circ} 366 / 11$.

\section{RESULTADOS E DISCUSSÃO}

Os trinta participantes do presente estudo eram predominantemente do sexo feminino (82\%). A faixa etária que prevaleceu foi entre 20 a 30 anos de idade (40\%). Quanto ao nível de escolaridade, $46 \%$ possuem o ensino fundamental completo. No que se refere ao grau de parentesco, o mais prevalente foi de familiares de primeiro grau, ou seja, mãe, pai, irmãos e filhos com $82 \%$. Outro aspecto analisado correspondeu ao tempo de hospitalização do paciente na UTI, a prevalência foi de um 1 a 20 dias (54\%).

A partir dos dados empíricos obtidos foi possível identificar quatro categorias emergentes: Orientações da equipe de enfermagem aos familiares de pacientes hospitalizados na UTI; Interação da equipe de enfermagem com familiares durante a visita; Uso de linguagem acessível à compreensão do familiar; e Sugestão dos familiares para melhoria da comunicação com a equipe de enfermagem.

\section{Orientações da equipe de enfermagem aos} familiares de pacientes hospitalizados na UTI

Esta categoria constata as orientações iniciais fornecidas pela equipe de enfermagem aos familiares que são necessárias para a realização da visita aos seus parentes hospitalizados na UTI. Seguem alguns depoimentos:
"Só algumas orientações gerais, coisas básicas... O horário, como tocar nele (paciente internado), mas que no ambiente, e nas máquinas não podia mexer. (F10)."

"Como entrar, lavar as mãos, essas coisas tive, mas quanto ao meu parente e os equipamentos não. (F29).”

A partir dos relatos identificou-se nas falas dos familiares uma deficiência nas orientações adequadas durante a visita ao paciente internado na UTI. A maioria foi de cuidados básicos, como lavagem das mãos e horário de visita, não havendo uma apresentação prévia da unidade e esclarecimento quanto aos equipamentos, ficando desinformados sobre o que vão encontrar junto ao seu parente.

Neste sentido, compreende-se que a equipe de enfermagem muitas vezes não informa previamente sobre o funcionamento da unidade e o estado do paciente aos familiares, os quais, normalmente, não estão preparados para ver o parente sedado e com tantos equipamentos. Por conseguinte, os familiares, muitas vezes, ficam chocados com o cenário e saem desesperados e chorosos, por não receberem uma explicação ou um consolo por parte da equipe (Rodrigues; Ferreira; Menezes, 2010).

Desse modo, estas pessoas devem ser preparadas para as visitas pela equipe de enfermagem, os quais lidam diretamente com o paciente, para que ao entrarem na UTI vivenciem este momento com menos estresse, possibilitando um contato mais próximo e afetivo com o parente hospitalizado.

Percebe-se ainda em outros depoimentos dos parentes que eles não tiveram informações a respeito das condições de saúde do seu familiar, não sendo estabelecida uma comunicação efetiva, capaz de amenizar os sentimentos negativos vivenciados pelos mesmos, podendo ser observado nas seguintes falas: 


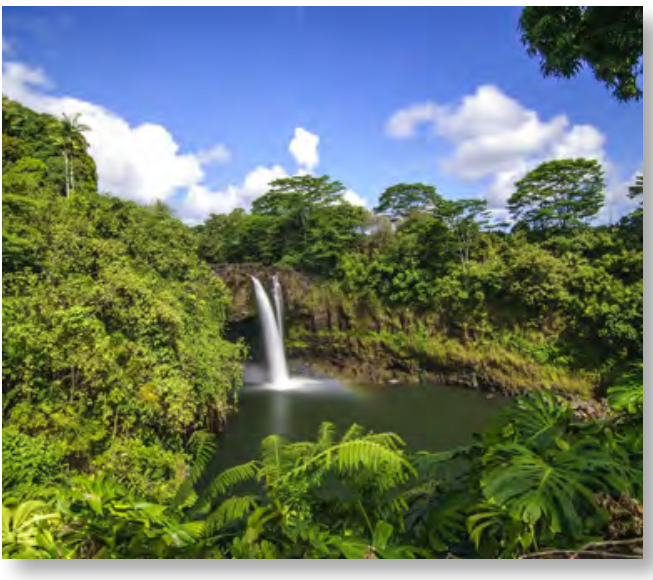

"Não, apenas afirmam que está grave, é como se escondessem algo [...] ficam algumas dúvidas no ar. (F1).”

"Gostaria de saber mais. Quando pergunto como tá, respondem apenas: - tá bem. (F2).”

"Às vezes eu tenho dúvida que elas escondem alguma coisa de mim. (F23).”

Os familiares relatam que não receberam nenhum tipo de orientação com relação à doença do seu ente hospitalizado na UTI. Observa-se também por meio das falas que eles não sentem segurança nas informações disponibilizadas pela equipe de enfermagem, alegando que permanecem com dúvidas em relação a estas informações considerando-as incompletas e insuficientes para a compreensão do real estado de saúde de seu familiar. É dever da enfermagem disponibilizar informações e esclarecimentos ao cliente e à família a respeito dos direitos, riscos, benefícios e intercorrências acercada assistência de enfermagem." (Brasil, 2007).

Nesta perspectiva, receber informações a respeito do estado do paciente na UTI, para os visitantes, consiste no conteúdo mais importante da comunicação entre eles e os profissionais. Dessa forma, uma medida prática seria a adoção, pela equipe de enfermagem, de uma postura acolhedora, associada ao questionamento sistemático dos familiares, sobre quais dúvidas e o quanto gostaria de ser informado (Victor et al., 2003). Nesse contexto, é preciso que o enfermeiro seja capaz de qualificar e quantificar o menos possível as informações prestadas, para que possam ser assimiladas gradativamente, sem omissão, nem excesso de informações, respeitando o direito dos familiares e também amenizando sua dor e sofrimento.

\section{Tempo destinado pela equipe de enferma- gem à interação com os familiares}

Disponibilizar tempo para interagir com o familiar corresponde a um importante elemento da comunicação, pois permite que a família sinta-se mais segura ao saber que existem profissionais que podem e estão dispostos a ajudá-los. Logo, esta categoria averiguou se a equipe de enfermagem dedica-se a comunicação e interação com os familiares. Seguem os relatos:

"Não dedicam tempo [...] é como se a função deles fosse só cuidar do paciente. (F1)."

"Não, só chegaram e disseram que ele tá bem, que era pra esperar o horário de visita, porque tem outras pessoas também que estão precisando de mais cuidados. (F7).”

"Não, elas fazem o trabalho delas... Eu que chego até elas, converso, pergunto [...] elas dizem que não tem esse tempo. (F22)."

As falas revelam que a equipe de enfermagem não destina tempo algum durante o horário da visita para interagir com os familiares. É possível perceber que os parentes sentem-se excluídos, uma vez que os profissionais de enfermagem direcionam-se apenas aos cuidados com o paciente, como destacado na fala de F1. $\mathrm{O}$ relato $\mathrm{F} 22$ mostra que a iniciativa de interagir e de se comunicar parte muitas vezes dos parentes.

O tempo despendido pelos profissionais ao excesso de procedimentos e tarefas que um pa- 
ciente grave demanda, acaba muitas vezes por limitar o tempo dispensado à sua família. Desse modo, a habilidade da equipe de enfermagem em interagir com os familiares deve ser aprendida com as experiências pessoais e profissionais, e quando estabelecidas com sucesso, aperfeiçoam o tempo de trabalho e influenciam positivamente nos cuidados não apenas com o paciente, mas também com seus familiares (Söderström; Benzein; Saveman, 2003).

Estudo realizado em um hospital particular localizado no município de São Paulo foi evidenciado que, na percepção dos profissionais de enfermagem os aspectos que mais dificultam a comunicação com o familiar são: a falta de tempo, falta de pessoal, intercorrências e telefonemas. Alguns ainda relataram evitar os parentes para não perder tempo (Santos; Silva, 2006). Entretanto, essa atitude muitas vezes é percebida pelos familiares, gerando conflitos que acaba afastando-os dos seus entes queridos, por desconhecerem seus direitos a informações e acharem que sua presença e indagações podem está incomodando. Esta situação fica evidente nas manifestações discursivas abaixo:

"Parece que não querem falar com a gente, se distanciam, se afastam, acho que para as enfermeiras é mais trabalhoso ter que vir até nós. (F17)."

"A gente chega aí elas são tão duras, só fica pra lá e pra cá, não dão nem um bom dia a pessoa [...] às vezes fico até com medo de falar e ela nem responder. (F23)."

São muitos os aspectos que interferem negativamente na interação entre profissionais e familiares, como situações com alta demanda emocional e piora das condições clínicas do paciente, no qual a equipe de enfermagem muitas vezes se sente ineficaz e com dificuldade para oferecer assistência à família. Como consequência, os profissionais se distanciam, evitando um envolvimento pessoal com a família (Söderström; Benzein; Saveman, 2003).

Neste aspecto, deve-se considerar que a família contribui consideravelmente para a recuperação do paciente, mas para que isso aconteça, ela precisa ser orientada sobre as rotinas da UTI e informada do que está acontecendo com o seu familiar, para que se sinta acolhida, respeitada e cuidada. Por isso, é importante que a equipe de enfermagem permita sua presença, assegurando-lhe de que está a disposição para ajudar.

\section{Uso de linguagem acessível à compreensão do familiar}

Para que o objetivo da comunicação seja alcançado, é necessário que o receptor da mensagem compreenda de maneira correta as informações, o que exige clareza, objetividade e o uso de uma linguagem simples por parte do emissor. Desta forma, os profissionais de enfermagem ao interagir com os familiares de pacientes em UTI devem evitar o uso de termos técnicos, possibilitando o entendimento das informações disponibilizadas.

"Já falaram e perguntei o que significava. (F1)."

"É, eles falam alguns termos técnicos que usam aqui, mas aí eu pergunto [...] (F20).”

"Quando não entendo sou bem sincera, digo que fale o português rasteiro, não em termos científicos. (F26)."

"Já sim, perguntei, mas não obtive resposta. (F9)."

Nas falas foi possível constatar que os profissionais de enfermagem ao se comunicarem com os familiares utilizam termos técnicos, como mencionou F1 e F20. Percebeu-se ainda no relato de F9 que os profissionais não tiveram a preocupação de explicar o significado, 
dificultando uma aproximação entre a equipe e os familiares.

É preciso haver atenção para não desperdiçar as oportunidades durante os encontros com os familiares e nas discussões sobre os cuidados com pacientes terminais. Nesta perspectiva, a comunicação deve ser feita de modo claro e com termos que sejam compreensíveis pelos familiares, pois a utilização de expressões técnicas pode impedir que o significado e a intenção de algumas assertivas não sejam assimilados adequadamente, o que pode gerar conflitos e sensações de "abandono" no cuidado do paciente (Stapleton et al., 2006).

Com base nesse entendimento, a equipe de enfermagem deve utilizar a fala como uma importante ferramenta para ser compreendido e, assim, atingir o objetivo da interação com os familiares. Desse modo, devem proporcionar-lhe informações que ajudem a aliviar suas preocupações, utilizando uma linguagem acessível, simples e objetiva, buscando passar as orientações de modo que possa equiparar ao nível social e grau de escolaridade (Martins et al., 2012).

\section{Sugestão dos familiares para melhoria da co- municação}

Nesta categoria procurou-se investigar de que maneira o familiar gostaria de ser recebido pelos profissionais de enfermagem e como deveria ocorrer a comunicação entre eles. Seguem as principais falas:

"Acho que deveriam dar mais informações e considerar que o acompanhante está bastante abalado, mesmo que não demonstre, deve perguntar como está [...] comunicar sempre o estado do paciente sem ter que a gente perguntar. (F1)."

"Assim, mais apoio né? Dar força, saber conversar, dar informações. (F15).”
"Não só a equipe de enfermagem, mas todos devem ser mais humanizados. Os profissionais se acostumam com as situações e tornam-se desumanos. (F16)."

"Eu acho que eles têm por obrigação dizer o estado do paciente e dá uma palavra de encorajamento para o familiar. (F21)."

Diante dos depoimentos dos familiares pode-se perceber que os principais aspectos destacados referem-se à necessidade de se sentirem bem tratados e acolhidos. Além disso, reforçam a importância que atribuem a uma assistência de qualidade por parte da equipe de enfermagem, recebendo informações sobre a situação de saúde do parente hospitalizado. Para tanto, a tecnologia é importante para melhorar a saúde do paciente, porém, ela deve estar interligada num processo que envolve e desenvolve ações, atitudes e comportamentos que se fundamentam no conhecimento científico e técnico, em que a atenção, transmitido pela comunicação, é essencial para um cuidado humanizado (Salomé, 2011).

Estudo semelhante realizado no Estado do Rio de Janeiro mostrou que são poucas as ações de enfermagem direcionadas aos membros da família na UTI, e quando realizadas, muitas vezes são por ordens prescritivas de limitar, fixar e determinar. Compreendendo, desse modo, que há certo distanciamento no que se refere ao processo de comunicação (Gotardo; Silva, 2005).

Para tanto, o enfermeiro é considerado como um agente de mudança social, sendo uma forma de melhorar o isolamento destes pacientes, abrindo espaço para facilitar todas as formas possíveis de comunicação do paciente com o exterior. Desse modo, as visitas familiares é uma ferramenta de humanizar este contexto clínico, como também um fator relevante neste processo de envolvimento par- 
ticipativo do ambiente do paciente, as opiniões e as crenças dos profissionais (Siles-González; Solano-Ruiz, 2014).

Dessa forma, no que diz respeito à relação entre equipe de enfermagem e familiares, destaca-se a importância de um processo onde se predomine a relação terapêutica, pois não basta apenas reconhecer as dificuldades dos familiares, mas assegurar-lhes o direito de não serem desconsiderados, comunicando-os que podem usufruir de disponibilidade e apoio (Silveira et al., 2005). Para isso, os enfermeiros necessitam criar estratégias de comunicação para atender às necessidades dos familiares que vivenciam a súbita e inesperada internação de um ente querido em UTI (Söderström; Benzein; Saveman, 2003).

\section{CONSIDERAÇÕES FINAIS}

Os resultados obtidos possibilita a compreensão de que a hospitalização de um paciente em UTI faz com que sua família vivencie sentimentos de angústia, solidão e medo do que possa acontecer e mostra o quanto um familiar necessita dos cuidados da equipe de enfermagem para enfrentar esse momento difícil. Destacou-se que as orientações disponibilizadas pela equipe de enfermagem aos familiares se restringiram apenas a lavagem das mãos e ao horário de visita, não sendo oferecido apoio às necessidades emocionais da família, transformando a experiência da internação de um parente em UTI em um processo ainda mais negativo e frustrante.

Nesse contexto, a comunicação se revela essencial na assistência de enfermagem, uma vez que, quando desenvolvida de forma adequada, minimiza esses sentimentos. Como observado nos depoimentos, os familiares têm como principais necessidades: receber informações sobre o estado de saúde de seu parente e ser bem acolhido de forma digna e humanizada.

Portanto, para que a interação entre a equipe de enfermagem e familiares de pacientes internados em UTI ocorra de maneira eficaz, emerge a necessidade de incentivar a capacitação desses profissionais para o uso consciente da comunicação, um instrumento indispensável no cuidar, possibilitando auxiliar os pacientes e familiares a compreenderem seus problemas e, a partir desse entendimento, empregar as intervenções adequadas.

\section{REFERÊNCIAS}

- Bardin, L. (2009) Análise de conteúdo. Edição 70,Lisboa (Po)

- Conselho Federal de Enfermagem (Brasil) (2007) CO-

FEN. Resolução No 311 de 8 de fevereiro de 2007: aprova a reformulação do código de ética dos profissionais de Enfermagem. Rio de Janeiro: Conselho Federal de Enfermagem.

- Costa, S.C; Figueiredo, M.R.B; Schaurich, D. (2009) Humanização em Unidade de Terapia Intensiva Adulto (UTI): compreensões da equipe de enfermagem. Interface- Comunic. Saude, Educ. 13(1):571-80.

- Gotardo, G.I.B; Silva, C.A. (2005) O cuidado dispensado aos familiares na unidade de terapia intensiva. R. Enferm. UERJ. 13: 223-8.

- Martins, J.J; Nascimento, E.R.P. (2005) A tecnologia e a organização do trabalho da Enfermagem em UTI. ACM Arq. Catarin. Med. Santa Catarina. 34(4):23-7.

- Martins, K.P; Macedo-Costa, K.N.F; Costa, T.F; Rezende, L.C.M; Oliveira, D.S.T; Brito, S.S. (2012) Aspectos relacionados à comunicação terapêutica entre enfermeiro e paciente cirúrgico no momento da admissão. Rev enferm UFPE on line. 6(11):2793-9.

- Ministério da Saúde (Brasil) (1996) Conselho Nacional de Saúde, Comissão Nacional de Ética em Pesquisa. Resolução No 196 de 10 de outubro de 1996: aprova as diretrizes e normas regulamentadoras de pesquisa envolvendo seres humanos. Ministério da Saúde, Brasília .

- Nascimento, E.R.P; Trentini, M.O. (2004) Cuidado de enfermagem na unidade de terapia. intensiva (UTI): te- 
oria humanística de Paterson e Zderad. Rev Latino-am Enfermagem. 12(2):250-7.

- Oliveira, P.S; Nobrega, M.M.L; Silva, A.T; Filha, M.O.F. (2005) Comunicação terapêutica em enfermagem revelada nos depoimentos de pacientes internados em centro de terapia intensiva. Revista Eletrônica de Enfermagem. 7(1): 54-63. Disponível em: http://www.revistas.ufg.br/ index.php/fen/article/viewArticle/861/1034

- Oriá, M.O.B; Moraes, L.M.P; Victor, J.F. (2004) A comunicação como instrumento do enfermeiro para o cuidado emocional do cliente hospitalizado. Revista Eletrônica de Enfermagem. 6(2): 292-7. Disponível em: http:// www.fen.ufg.br/fen_revista/revista6_2/pdf/R4_comunica.pdf

- Rodrigues, M.V.C; Ferreira, E.D; Menezes, T.M.O. (2010) Comunicação da enfermeira com pacientes portadores de câncer fora de possibilidade de cura. Rev. enferm. UERJ, Rio de Janeiro, jan/mar.,18(1):86-91.

- Salomé, G.M. (2011) Comunicação entre pacientes e acadêmicos de enfermagem em unidade de terapia intensiva: abordagem fenomenológica. Nursing. jan., 13(152):32-38.

- Santos, K.M.A.B; Silva, M.J.P. (2006) Percepção dos pro- fissionais de saúde sobre a comunicação com os familiares de pacientes em UTIs. Rev Bras Enferm 59(1):61-6.

- Siles-González, J; Solano-Ruiz, C. (2014) Qualitative Research and Narrative Sources in the Context of Critical and Renal Cares. Open Journal of Nursing. 4, 385-401. Disponível em: http://dx.doi.org/10.4236/ ojn. 2014.46045

- Silveira, R.S; Lunardi, V.L; Lunardi Filho, W.D; Oliveira, A.M.N. (2005) Uma tentativa de humanizar a relação da equipe de enfermagem com a família de pacientes internados na UTI. Texto Contexto Enferm, Florianópolis. 14(Esp.): 125-30.

- Söderström, I.M; Benzein, E; Saveman, B.I. (2003) Nurses, experiences of interactions with family members in intensive care units. Scand J Caring Sci. 17(2): 185-92

- Stapleton, R.D; Engelberg, R.A; Wenrich, M.D; Goss, C.H; Curtis, J.R. (2006) Clinician statements and family satisfaction with family conferences in the intensive care unit. Crit Care Med. 34:1679-1685.

- Victor, A.C.S; Matsuda, L.M; Saalfeld, S.M.S; Évora, Y.D.M. (2003) Comunicação verbal de uma equipe médica: percepções e necessidades de visitantes de uma UTI. Acta Scientiarum. Health Sciences. 25(2):199-206.

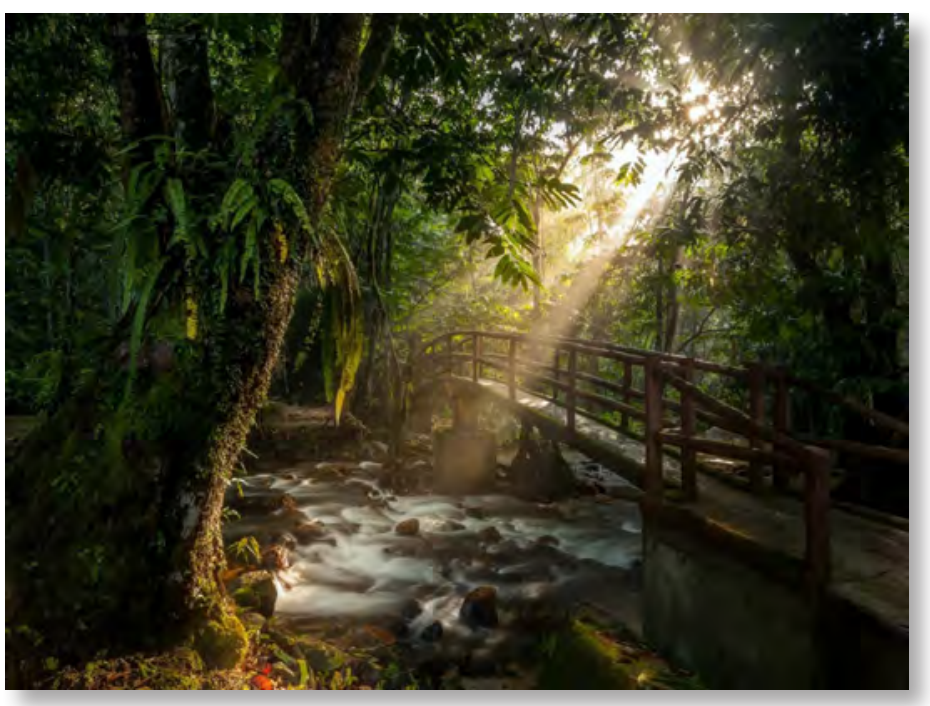

